\title{
Validation and Gender-Based Comparison of the Eating Behavior Scale for Japanese Young Adults
}

\author{
Masami Horiguchi ${ }^{*}$, Gohichi Tanaka ${ }^{2}$, Haruko Ogasawara ${ }^{3}$, Ryoko Maruyama4 \\ ${ }^{1}$ Department of Nursing, School of Health Sciences, Sapporo Medical University, Sapporo, Japan \\ ${ }^{2}$ Department of Psychology, Center for Medical Education, Sapporo Medical University, Sapporo, Japan \\ ${ }^{3}$ Health Sciences, Hokkaido University Graduate School of Education, Sapporo, Japan \\ ${ }^{4}$ Health Sciences, Graduate School of Medicine, Tohoku University, Sendai, Japan \\ Email: ${ }^{*}$ hori@sapmed.ac.jp
}

Received 11 October 2014; revised 11 November 2014; accepted 8 December 2014

Copyright (C) 2014 by authors and Scientific Research Publishing Inc.

This work is licensed under the Creative Commons Attribution International License (CC BY).

http://creativecommons.org/licenses/by/4.0/

(c) (i) Open Access

\begin{abstract}
Young adulthood is a time when eating behaviors can become disturbed. In general, women want to lose weight, and men want to gain weight in the form of muscle. A convenient tool to assess characteristics of eating behavior in young adulthood is needed in order to promote a healthy diet. The first aim of this study was to develop an eating behavior scale for Japanese young adults (EBS). The secondary aim was to compare eating behaviors between men and women. The EBS was modified from a questionnaire directed at high school students by Tayama and colleagues (Tayama, Watanabe, Nishimura, Murakami, \& Fukudo, 2008). The participants of this study were 794 Japanese young adults (404 men and 390 women) enrolled at three universities and two vocational schools in Japan. They were recruited in the classroom and were asked to submit the completed EBS questionnaire if they agreed to participate. We assessed the validity of the EBS and compared factors between men and women. Three subscales were extracted from the EBS: "Extrinsic eating" (e.g., eating when others eat or when feeling irritated), "Eating quickly" (e.g., eating quickly or not chewing food well), and "Strong taste" (e.g., liking strong-tasting or greasy food). Overall EBS score and "Extrinsic eating" were higher, and "Strong taste" was lower, in women than that in men. The findings indicate that the EBS is suitable as a simple tool to assess properties of eating behavior of healthy Japanese young adults.
\end{abstract}

\section{Keywords}

Eating Behavior Scale, Japanese Young Adults, Factor Analysis, Gender-Based Comparison

\footnotetext{
Corresponding author.
}

How to cite this paper: Horiguchi, M., Tanaka, G., Ogasawara, H., \& Maruyama, R. (2014). Validation and Gender-Based Comparison of the Eating Behavior Scale for Japanese Young Adults. Psychology, 5, 2173-2179. 


\section{Introduction}

Obesity and underweight can cause a number of health problems. Obesity is associated with cardiovascular disease, increased mortality, decreased quality of life, and increased economic burden on society (Cornier, Marshall, Hill, Maahs, \& Eckel, 2011). Adults who were normal body weight with diabetes had higher mortality than adults who were overweight or obese (Carnethon et al., 2012). In the case of people who are underweight, risks of cerebrovascular disease and infection are higher (Tsugane, 2012). Being underweight is also a risk factor for osteoporosis (Chang \& Yang, 2013; Tanaka, Kuroda, Saito, \& Shiraki, 2013). Future osteoporosis can be prevented through the development of bone mass during adolescence and puberty (Tandon et al., 2012; Gafni \& Baron, 2007). It has also been suggested that there is an influence of embryonic development on osteoporosis (Holroyd, Harvey, Dennison, \& Cooper, 2012). Therefore, lean adolescent women may cause not only risk of lifestyle-related diseases for themselves, but also osteoporosis in future generations.

Both obesity and underweight are associated with lifestyle, such as eating and exercise habits. Eating habits are related to the intake of energy and nutrients, and exercise habits are related to the consumption of energy and nutrients. Furthermore, the desire to lose weight moderates the relationship between objective binge eating episodes, body image concerns, and inappropriate compensatory behaviors (De Young, Lavender, \& Anderson, 2010). In terms of Japanese young women oriented toward being slim, perception of body image affects diet, sleep, and exercise (Mori, Sekine, Yamagami, \& Kagamimori, 2009). In contrast, men who are thin or have normal weight have an almost accurate body image of themselves, while overweight or obese men tend to underestimate their body size (Gardner, 2014). In addition, men usually desire to be more muscular (De Young et al., 2010). Therefore, there are differences in the characteristics of eating behaviors between men and women (Forrester-Knauss \& Stutz, 2012).

Body mass index (BMI) for adults is classified as follows: Underweight, BMI < 18.5; Normal weight, BMI 18.5 - 24.9; Overweight, BMI 25.0 - 29.9; Obese, BMI > 30.0 (Centers for Disease Control (CDC), 2014). The proportion of Japanese individuals over the age of 20 whose BMI was 25.0 or more was 29.1\% for men and 19.4\% for women in 2012 (Ministry of Health, Labour and Welfare, 2014). The proportion of individuals with a BMI 25.0 or greater was $15.2 \%$ in men and $7.8 \%$ in women. In contrast, the proportion of Japanese individuals with a BMI less than 18.5 was $4.2 \%$ in men and $11.4 \%$ in women over the age of 20 , and $7.2 \%$ in men and $21.8 \%$ in women in the 20 to 29-year-old age group. The proportion of lean individuals among 20- to 29-yearold women was the highest, when compared to other age groups (Ministry of Health, Labour and Welfare, 2014). We regard the strong desire to be slim among young women as the reason for this high ratio of lean women in Japan (Hayashi, Takimoto, Yoshita, \& Yoshiike, 2006). When the BMI of Japanese young women (aged 15 - 29 years) was compared every five years, the average BMI had decreased (Takimoto, Yoshiike, Kaneda, \& Yoshita, 2004). In particular, the proportion of underweight adolescent women was particularly high in Japan.

The proportion of low-birth-weight (LBW) babies of less than $2500 \mathrm{~g}$ has also increased in Japan. The proportion of LBW babies was 6.5\% in 1991, 8.8\% in 2001, and 9.6\% in 2011; thus, the proportion of LBW babies has increased 1.5-fold in the past 20 years (Organisation for Economic Co-operation and Development (OECD), 2014). The proportion of $9.6 \%$ in Japan was second to the proportion of 9.8\% in Greece in 2011 (OECD, 2014 ). The ratio of LBW babies in Korea increased from 4.0\% in 2001 to 5.2\% in 2011, but the ratio in Korea was less than the ratio in Japan (OECD, 2014). The increase in the proportion of lean women and LBW babies has attracted attention in terms of particular health problems connected with the Japanese.

Various questionnaires have been developed to measure different aspects of eating behaviors. Questionnaires about eating behaviors of the Japanese have been directed at only women, or adult men and women, and the number of questions has ranged from 30 - 50 items. For example, in terms of screening for eating disorders, the Scottish Colloquium on Food and Feeding (SCOFF) has been developed as a simple self-assessment tool that addresses core features of anorexia nervosa and bulimia nervosa (Morgan, Reid, \& Lacey, 1999). The SCOFF appeared highly effective as a screening tool for eating disorders in a three-stage study: Study 1 tested the instrument with clinical cases and controls; Study 2 examined the reliability of verbal versus written administrations, and Study 3 validated its use as a screening tool in primary care (Hill, Reid, Morgan, \& Lacey, 2010). Another questionnaire assesses "shifts" or "habits” of eating behavior in obese individuals (Sakata, 1996, in Japanese). This diet activities scale consists of 50 items for adult men and women, with items such as "when other people eat, I eat with them”, and “I do not chew my food well” (Sakata, 1996, in Japanese). Another scale has been developed to reflect self-determination theory for healthy eating behaviors (Pelletier, Dion, Slovinec- 
D’Angelo, \& Reid, 2004), rather than psychopathological eating disorders.

Furthermore, Kato and colleagues evaluated the psychometric properties of a Japanese version of the Motivation for Healthy Eating Scale, which modified the original 31-item questionnaire (Kato, Iwanaga, Roth, Hamasaki, \& Greimel, 2013). The 31 items of the Japanese eating behaviors questionnaire focused on motivation for healthy eating (Kato et al., 2013). Finally, Tayama and colleagues developed an eating behavior scale for Japanese high school students with reference to the questionnaire of eating behavior by Tayama (Tayama et al., 2008). This 30-item questionnaire includes five subscales: “eating as diversion”, "overfeeding”, "eating quickly”, "irregular eating", and "content of meals". Cronbach's alpha coefficients generally indicated acceptable reliability (>0.70): "eating as diversion”, 0.65; "overfeeding”, 0.70; “eating quickly", 0.63; "irregular eating”, 0.73; and "content of meals", 0.75 (Tayama et al., 2008). Tayama and colleagues reported that eating as diversion, overfeeding, and irregular eating became more prevalent among late-adolescent women (Tayama, Nishiura, \& Sugawara, 2010). However, most of the questionnaires discussed contain many items and can be inconvenient to use when combined with other indicators and assessments, as the burden on participants is increased and usability is restricted.

Eating behavior is controlled by physiological mechanisms in the brain and modified by socio-cultural factors. Therefore, studies of eating behavior must employ tools that measure characteristics that take into account socio-cultural factors. The first aim of this study was to develop an eating behavior scale for Japanese young adults (EBS), which was a modified version of the high school students' version by Tayama and colleagues (Tayama et al., 2008). The secondary aim was to compare eating behaviors between men and women.

\section{Methods}

\subsection{Participants}

The participants of this study were 794 Japanese undergraduate students (404 men, and 390 women) aged under 30 years old, who belonged to the faculties of medicine, health sciences, social welfare, education, or the medical vocational college in Sapporo and suburbs of Japan. University course instructors (e.g., health psychology, psychology) were invited to recruit students in their classes. Students were asked to complete and submit the EBS questionnaire if they consented to participate: almost $100 \%$ of students submitted the questionnaire. The average age of participants was 19.8 years $(\mathrm{SD}=1.9)$ : 20.4 years $(\mathrm{SD}=2.2)$ for men and 19.3 years $(\mathrm{SD}=1.3)$ for women. Participants were provided with a written description informing them of the purpose of the study. The research protocol was approved by the Ethics Committee of the Sapporo Medical University.

\subsection{Instruments}

The EBS questionnaire was a modified version of the high school students version by Tayama and colleagues (Tayama et al., 2008), adapted for use with college students. One item ("I do not have time to eat at leisure") was deleted from the original questionnaire, and two items were added ("I like food with a strong taste" and "I often eat snacks between meals or late at night"). The modified version of the EBS was designed to assess eating behaviors and opportunities for eating behaviors. Items were as follows: "I eat quickly", "I am told that I eat too much", "I like greasy food", "I eat irregularly", "I eat until I am full”, "I eat if I am irritated", "When other people eat, I eat with them", "I like food with a strong taste", "I do not eat breakfast", "I would eat fruit and candy placed before me", "I can eat whatever I like after mealtime”, "I do not chew my food well", "I regret it after I have eaten a lot", and "I often eat snacks between meals or late at night". Participants completed the questionnaire at universities or vocational colleges. Items were rated on a four-point scale: 1 (never), 2 (very rarely), 3 (sometimes), and 4 (very often). Factor analysis was performed, and a factor structure chosen. We calculated the average value of the subscale raw scores for each participant. The total score was calculated as the average value of the subscale scores.

\subsection{Statistical Analysis}

All analyses were carried out using IBM SPSS Version 20.0 (IBM Japan Inc., Tokyo, Japan). Means and standard deviations were calculated for the data. Factor analysis of the EBS questionnaire was conducted using principle factor method and promax rotation. The number of factors was determined using a scree plot and interpretability of the factors. Factor loadings and Cronbach's alpha coefficients were calculated. To examine gender 
differences in the EBS, subscale means and standard deviations were calculated by gender, and t-tests and correlation analyses were performed. $p$ values less than 5 percent were considered significant.

\section{Results}

\subsection{Factor Analysis of the Eating Behavior Scale}

Mean scores for each item of the EBS were in the range of 1.76 to 2.93 points. Frequency distributions of the following three items were not normal: "I am told that I eat too much", "I do not eat breakfast", and "I regret it after I have eaten a lot". However, since these items were considered necessary to assess aspects of eating behaviors, they were included in the factor analysis of all 14 items.

The factor structure of the EBS was examined using factor analysis with a principal factor method. We performed a screen test, and chose a three-factor structure based on the point at which the eigenvalues (3.69, 1.80, $1.43,1.16,0.93$ ) began to level out in the scree plot. Three items without sufficient factor loadings were then excluded from the factor analysis: "I eat irregularly", "I eat until I am full”, and "I do not eat breakfast". Again, we used factor analysis with a principal factor method and promax rotation. Resultant factor loadings and correlations among the extracted factors are presented in Table 1. Three subscales were extracted: "Extrinsic eating", "Eating quickly", and "Strong taste". The total variance of the 11 items in the three factors was $49.39 \%$.

Factor 1 (Extrinsic eating) was composed of six items: "When other people eat, I eat with them", "I eat if I am irritated", "I can eat whatever I like after mealtime”, "I would eat fruits and candy placed before me”, "I regret it after I have eaten a lot", and "I often eat snacks between meals or late at night”. Factor 2 (Eating quickly) was composed of three items: "I eat quickly", "I do not chew my food well", and "I am told that I eat too much". Factor 3 (Strong taste) was composed of two items: "I like food with a strong taste", and "I like greasy food".

Factor scores of each subscale were defined as the mean of the scores of each item. The overall score of the EBS was defined as the mean of the three subscales. The mean scores for the three subscales and the overall score of the EBS were as follows: "Extrinsic eating", 2.59 (SD = 0.66); "Eating quickly", 2.31 (SD = 0.75); "Strong taste", 2.52 ( $\mathrm{SD}=0.83$ ); overall EBS score, 2.47 ( $\mathrm{SD}=0.53$ ). Cronbach's alpha coefficients were as follows: "Extrinsic eating”, 0.75; "Eating quickly", 0.69; and "Strong taste”, 0.68.

\begin{tabular}{|c|c|c|c|c|}
\hline \multirow{2}{*}{$\begin{array}{c}\text { Item } \\
\text { number }\end{array}$} & \multirow{2}{*}{ Items } & \multicolumn{3}{|c|}{ Factor loadings } \\
\hline & & Factor 1 & Factor 2 & Factor 3 \\
\hline 7 & When other people eat, I eat with them. & 0.71 & 0.01 & -0.04 \\
\hline 6 & I eat if I am irritated. & 0.67 & 0.03 & -0.07 \\
\hline 11 & I can eat whatever I like after mealtime. & 0.59 & -0.01 & -0.02 \\
\hline 10 & I would eat fruits and candy placed before me. & 0.57 & -0.11 & 0.16 \\
\hline 13 & I regret it after I have eaten a lot. & 0.56 & 0.07 & -0.14 \\
\hline 14 & I often eat snacks between meals or late at night. & 0.4 & -0.03 & 0.24 \\
\hline 1 & I eat quickly. & -0.08 & 0.98 & -0.04 \\
\hline 12 & I do not chew my food well. & 0.03 & 0.56 & 0.1 \\
\hline 2 & I am told that I eat too much. & 0.32 & 0.36 & 0.05 \\
\hline 8 & I like food with a strong taste. & -0.03 & -0.03 & 0.73 \\
\hline \multirow[t]{5}{*}{3} & I like greasy food. & -0.03 & 0.11 & 0.69 \\
\hline & Factor correlation & Factor 1 & Factor 2 & Factor 3 \\
\hline & Factor 1 & - & 0.3 & 0.25 \\
\hline & Factor 2 & & - & 0.26 \\
\hline & Factor 3 & & & - \\
\hline
\end{tabular}


Correlation analyses between the subscales of the EBS indicated significant positive correlations: "Extrinsic eating" and "Eating quickly", $\mathrm{r}=0.33(p<0.01)$; "Extrinsic eating" and "Strong taste", $\mathrm{r}=0.17(p<0.01)$; and "Eating quickly" and "Strong taste", $\mathrm{r}=0.26(p<0.01)$.

\subsection{Comparison between Men and Women}

$T$-tests for the means of the overall and subscale scores of the EBS were performed between men and women. The overall score of the EBS $(t=3.35, \mathrm{df}=792, p<0.01)$, and "Extrinsic eating" $(t=13.52, \mathrm{df}=792, p<0.01)$ were higher for women than men. "Strong taste" was higher for men than women $(t=3.06, \mathrm{df}=792, p<0.01)$, and "Eating quickly" showed no significant differences between men and women (Table 2).

\section{Discussion}

The purpose of this study was to develop an eating behavior scale with fewer items than existing instruments. The present study developed a simple 11-item eating behavior scale for young adults. Factor analysis revealed three factors of the EBS for Japanese young adults: "Extrinsic eating”, "Eating quickly", and "Strong taste". Internal consistency of these factors was confirmed by Cronbach's alpha coefficients between 0.68 and 0.75 . Cronbach's alpha coefficient and internal consistency would increase with additional items; however, this would impair the convenience of the tool. Thus, the reliability was deemed acceptable in order to retain a shorter instrument.

Positron emission tomography (PET) (Wang et al., 2009), functional magnetic resonance imaging (fMRI) (Cornier, Salzberg, Endly, Bessesen, \& Tregellas, 2010), and magnetic resonance imaging (MRI) (Horstmann et al., 2011) have been used in studies of food intake regulation, and gender differences have been demonstrated. Leptin and insulin are involved in the regulation of body weight and long-term ingestion of food (Baskin et al., 1999), and gender differences have been reported in relation to leptin and adiponectin (Andreasson, Undén, Elofsson, \& Brismar, 2012), and leptin, C-reactive protein, and cardiovascular risk factors (Chiu et al., 2012). The relation between obesity and emotional state in obese women has also been studied (Capuron et al., 2011). The present 11-item EBS clarified gender differences in Japanese young adults aged 18 - 30 years. "Strong taste" was higher in men than in women and "Extrinsic eating" and the overall score of the EBS were higher in women than in men (Table 2). These results indicate that strong taste and greasy food may be related to eating behavior in men, whereas the environment, other people eating, and psychological factors such as being irritated trigger eating behavior in women. Our findings indicate that the EBS is suitable as a simple tool to assess gender differences in eating behavior. Namely, we were able to examine gender differences in healthy eating behaviors associated with physiological and psychological indices for Japanese young adults.

Limitations of the present study are as follows. Appetite of women is enhanced by action of the corpus luteum hormone; however, the present study did not consider menstrual cycles. Therefore, there is a need to add an item for eating behaviors related to the menstrual cycle. Another limitation was that the participants were recruited from the faculties of medicine, health sciences, social welfare, and education, and vocational college of medicine; therefore, the results may not be generalizable to all young adults in Japan. Cronbach's alpha coefficients for the EBS subscales "Eating quickly" (0.69) and "Strong taste" $(0.68)$ are below the minimum level of alpha coefficient for social science research. Therefore, the reliability of the modified questionnaire is not good

Table 2. Means (M) and standard deviations (SD) of the eating behavior scale.

\begin{tabular}{ccccccc}
\hline \multirow{2}{*}{ Factors } & \multicolumn{2}{c}{ Men $(\mathrm{n}=404)$} & & \multicolumn{2}{c}{ Women $(\mathrm{n}=390)$} & \multirow{2}{*}{ t-score } \\
\cline { 2 - 5 } & $\mathrm{M}$ & $(\mathrm{SD})$ & $\mathrm{M}$ & $(\mathrm{SD})$ & \\
\hline $\begin{array}{c}\text { Overall eating behavior score } \\
\text { Subscales }\end{array}$ & 2.41 & $(0.53)$ & & 2.53 & $(0.52)$ & $3.35^{* *}$ \\
Extrinsic eating & & & & & \\
Eating quickly & 2.31 & $(0.59)$ & 2.88 & $(0.60)$ & $13.52^{* *}$ \\
Strong taste & 2.31 & $(0.76)$ & 2.30 & $(0.74)$ & 0.34 \\
\hline Note: ${ }^{* *} p<0.01$. & 2.61 & $(0.82)$ & 2.43 & $(0.82)$ & $3.06^{* *}$ \\
\hline
\end{tabular}


enough. Finally, future research must examine the validity of physiological and psychological indices related to eating behaviors.

\section{Conclusion}

The present study showed that the EBS, which consisted of three subscales, was suitable as a simple tool to assess aspects of eating behaviors in healthy Japanese young adults. The three subscales of the EBS were "Extrinsic eating," "Eating quickly," and "Strong taste." The overall EBS score and "Extrinsic eating” were higher, and "Strong taste" was lower, in women than that in men.

\section{Conflict of Interest}

The authors declare no conflict of interest.

\section{Acknowledgements}

This study was supported in part by Grant-in-Aid for Scientific Research (C) (21592855) from the Japan Society for the Promotion of Science.

\section{References}

Andreasson, A. N., Undén, A. L., Elofsson, S., \& Brismar, K. (2012). Leptin and Adiponectin: Distribution and Associations with Cardiovascular Risk Factors in Men and Women of the General Population. American Journal of Human Biology, 24, 595-601. http://dx.doi.org/10.1002/ajhb.22279

Baskin, D. G., Lattemann, D. F., Seeley, R. J., Woods, S. C., Porte Jr., D., \& Schwartz, M. W. (1999). Insulin and Leptin: Dual Adiposity Signals to the Brain for the Regulation of Food Intake and Body Weight. Brain Research, 848, 114-123. http://dx.doi.org/10.1016/S0006-8993(99)01974-5

Capuron, L., Poitou, C., Machaux-Tholliez, D., Frochot, V., Bouillot, J.-L., Basdevant, A., Layé, S., \& Clément, K. (2011). Relationship between Adiposity, Emotional Status and Eating Behaviour in Obese Women: Role of Inflammation. Psychological Medicine, 41, 1517-1528. http://dx.doi.org/10.1017/S0033291710001984

Carnethon, M. R., De Chavez, P. J. D., Biggs, M. L., Lewis, C. E., Pankow, J. S., Bertoni, A. G., Golden, S. H., Liu, K., Mukamal, K. J., Camphell-Jenkins, B., \& Dyer, A. R. (2012). Association of Weight Status with Mortality in Adults with Incident Diabetes. The Journal of the American Medical Association, 308, 581-590.

Centers for Disease Control Website (2014). Body Mass Index. http://www.cdc.gov/healthyweight/assessing/bmi/adult_bmi/index.html\#Interpreted

Chang, S. F., \& Yang, R. S. (2013). Determining the Cut-Off Point of Osteoporosis Based on the Osteoporosis Self-Assessment Tool, Body Mass Index and Weight in Taiwanese Young Adult Women. Journal of Clinical Nursing, 23, 2628-2636. http://dx.doi.org/10.1111/jocn.12483

Chiu, F.-H., Chuang, C. H., Li, W. C., Weng, Y. M., Fann, W.-C., Lo, H.-Y., Sun, C., \& Wang, S. H. (2012). The Association of Leptin and C-Reactive Protein with the Cardiovascular Risk Factors and Metabolic Syndrome Score in Taiwanese Adults. Cardiovascular Diabetology, 11, 40-48. http://dx.doi.org/10.1186/1475-2840-11-40

Cornier, M. A., Salzberg, A. K., Endly, D. C., Bessesen, D. H., \& Tregellas, J. R. (2010). Sex-Based Differences in the Behavioral and Neuronal Responses to Food. Physiology \& Behavior, 99, 538-543.

http://dx.doi.org/10.1016/j.physbeh.2010.01.008

Cornier, M. A., Marshall, J. A., Hill, J. O., Maahs, D. M., \& Eckel, R. H. (2011). Prevention of Overweight/Obesity as a Strategy to Optimize Cardiovascular Health. Circulation, 124, 840-850. http://dx.doi.org/10.1161/CIRCULATIONAHA.110.968461

De Young, K. P., Lavender, J. M., \& Anderson, D. A. (2010). Binge Eating Is Not Associated with Elevated Eating, Weight, or Shape Concerns in the Absence of the Desire to Lose Weight in Men. International Journal of Eating Disorders, 43, 732-736.

Forrester-Knauss, C., \& Stutz, E. Z. (2012). Gender Differences in Disordered Eating and Weight Dissatisfaction in Swiss Adults: Which Factors Matter? BMC Public Health, 12, 809. http://dx.doi.org/10.1186/1471-2458-12-809

Gafni, R. I., \& Baron, J. (2007). Childhood Bone Mass Acquisition and Peak Bone Mass May Not Be Important Determinants of Bone Mass in Late Adulthood. Pediatrics, 119, S131-S136. http://dx.doi.org/10.1542/peds.2006-2023D

Gardner, R. M. (2014). Weight Status and the Perception of Body Image in Men. Psychology Research and Behavior Management, 7, 175-184. http://dx.doi.org/10.2147/PRBM.S49053 
Hayashi, F., Takimoto, H., Yoshita, K., \& Yoshiike, N. (2006). Perceived Body Size and Desire for Thinness of Young Japanese Women: A Population-Based Survey. British Journal of Nutrition, 96, 1154-1162. http://dx.doi.org/10.1017/BJN20061921

Hill, L. S., Reid, F., Morgan, J. F., \& Lacey, J. H. (2010). SCOFF, The Development of an Eating Disorder Screening Questionnaire. International Journal of Eating Disorders, 43, 344-351.

Holroyd, C., Harvey, N., Dennison, E., \& Cooper, C. (2012). Epigenetic Influences in the Developmental Origins of Osteoporosis. Osteoporosis International, 23, 401-410. http://dx.doi.org/10.1007/s00198-011-1671-5

Horstmann, A., Busse, F. P., Mathar, D., Müller, K., Lepsien, J., Schlögl, H., Kabish, S., Kratzsch, J., Neumann, J., Stumvoll, M., Villringer, A., \& Pleger, B. (2011). Obesity-Related Differences between Women and Men in Brain Structure and Goal-Directed Behavior. Frontiers in Human Neuroscience, 5, 1-9. http://dx.doi.org/10.3389/fnhum.2011.00058

Kato, Y., Iwanaga, M., Roth, R., Hamasaki, T., \& Greimel, E. (2013). Psychometric Validation of the Motivation for Healthy Eating Scale (MHES). Psychology, 4, 136-141. http://dx.doi.org/10.4236/psych.2013.42020

Ministry of Health, Labour and Welfare (2014). Outline of the Results from the 2012 National Health and Nutrition Survey. http://www.mhlw.go.jp/file/04-Houdouhappyou-10904750-Kenkoukyoku-Gantaisakukenkouzoushinka/0000032813.pdf

Morgan, J. F., Reid, E., \& Lacey, J. H. (1999). The SCOFF Questionnaire: Assessment of a New Screening Tool for Eating Disorders. British Medical Journal, 319, 1467-1468. http://dx.doi.org/10.1136/bmj.319.7223.1467

Mori, K., Sekine, M., Yamagami, T., \& Kagamimori, S. (2009). Relationship between Body Image and Lifestyle Factors in Japanese Adolescent Girls. Pediatrics International, 51, 507-513. http://dx.doi.org/10.1111/j.1442-200X.2008.02771.x

Organization for Economic Cooperation and Development/StatExtracts (2014) Complete Databases Available via OECD’s iLibrary, Health Status: Infant Health, Low Birthweight. http://stats.oecd.org/

Pelletier, L. G., Dion, S. C., Slovenic-D’Angelo, M., \& Reid, R. (2004). Why Do You Regulate What You Eat? Relationships between Forms of Regulation, Eating Behaviors, Sustained Dietary Behavior Change, and Psychological Adjustment. Motivation and Emotion, 28, 245-277. http://dx.doi.org/10.1023/B:MOEM.0000040154.40922.14

Sakata, T. (1996). Obesity Treatment Manual. Ishiyaku Publishers, Inc., Tokyo, 32-37.

Takimoto, H., Yoshiike, N., Kaneda, F., \& Yoshita, K. (2004). Thinness among Young Japanese Women. American Journal of Public Health, 94, 1592-1595. http://dx.doi.org/10.2105/AJPH.94.9.1592

Tanaka, S., Kuroda, T., Saito, M., \& Shiraki, M. (2013). Overweight/Obesity and Underweight Are Both Risk Factors for Osteoporosis Fractures at Different Sites in Japanese Postmenopausal Women. Osteoporosis International, 24, 69-76. http://dx.doi.org/10.1007/s00198-012-2209-1

Tandon, N., Fall, C. H. D., Osmond, C., Sachdev, H. P., Prabhakaran, D., Ramakrishnan, L., Biswas, S. K. D., Ramji, S., Khalil, A., Gera, T., Reddy, K. S., Barker, D. J. P., Cooper, C., \& Bhargava, S. K. (2012). Growth from Birth to Adulthood and Peak Bone Mass and Density Data from the New Delhi Birth Cohort. Osteoporosis International, 23, $2447-2459$. http://dx.doi.org/10.1007/s00198-011-1857-x

Tayama, J., Nishiura, K., \& Sugawara, M. (2010). A Psychological Research of Abnormal Eating Behaviors in Adolescent Women. Journal of Clinical Research Center for Child Development and Educational Practice, 9, 117-124. (In Japanese with English Abstract)

Tayama, J., Watanabe, S., Nishiura, K., Munakata, M., \& Fukudo, S. (2008). Development of an Eating Behavior Scale for High School Students and Study on the Factors Related to Himando. Japanese Journal of Psychosomatic Medicine, 48, 217-227. (In Japanese with English Abstract)

Tsugane, S. (2012). Alcohol, Smoking, and Obesity Epidemiology in Japan. Journal of Gastroenterology and Hepatology, 27, 121-126. http://dx.doi.org/10.1111/j.1440-1746.2011.07021.x

Wang, G. J., Volkow, N. D., Telang, F., Jayne, M., Ma, Y., Pradhan, K., Zyu, W., Wong, C. T., Thanos, P. K., Geliebter, A., Biegon, A., \& Fowler, J. S. (2009). Evidence of Gender Differences in the Ability to Inhibit Brain Activation Elicited by Food Stimulation. Proceedings of the National Academy of Sciences, 106, 1249-1254. http://dx.doi.org/10.1073/pnas.0807423106 
Scientific Research Publishing (SCIRP) is one of the largest Open Access journal publishers. It is currently publishing more than 200 open access, online, peer-reviewed journals covering a wide range of academic disciplines. SCIRP serves the worldwide academic communities and contributes to the progress and application of science with its publication.

Other selected journals from SCIRP are listed as below. Submit your manuscript to us via either submit@scirp.org or Online Submission Portal.
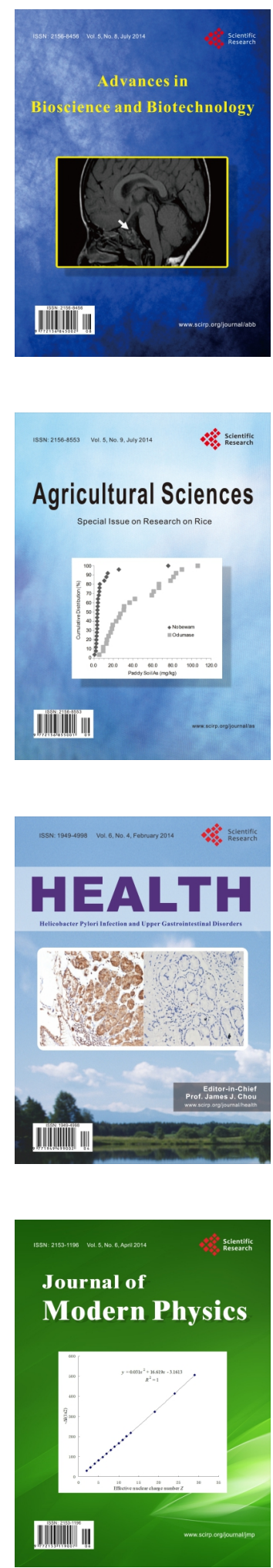
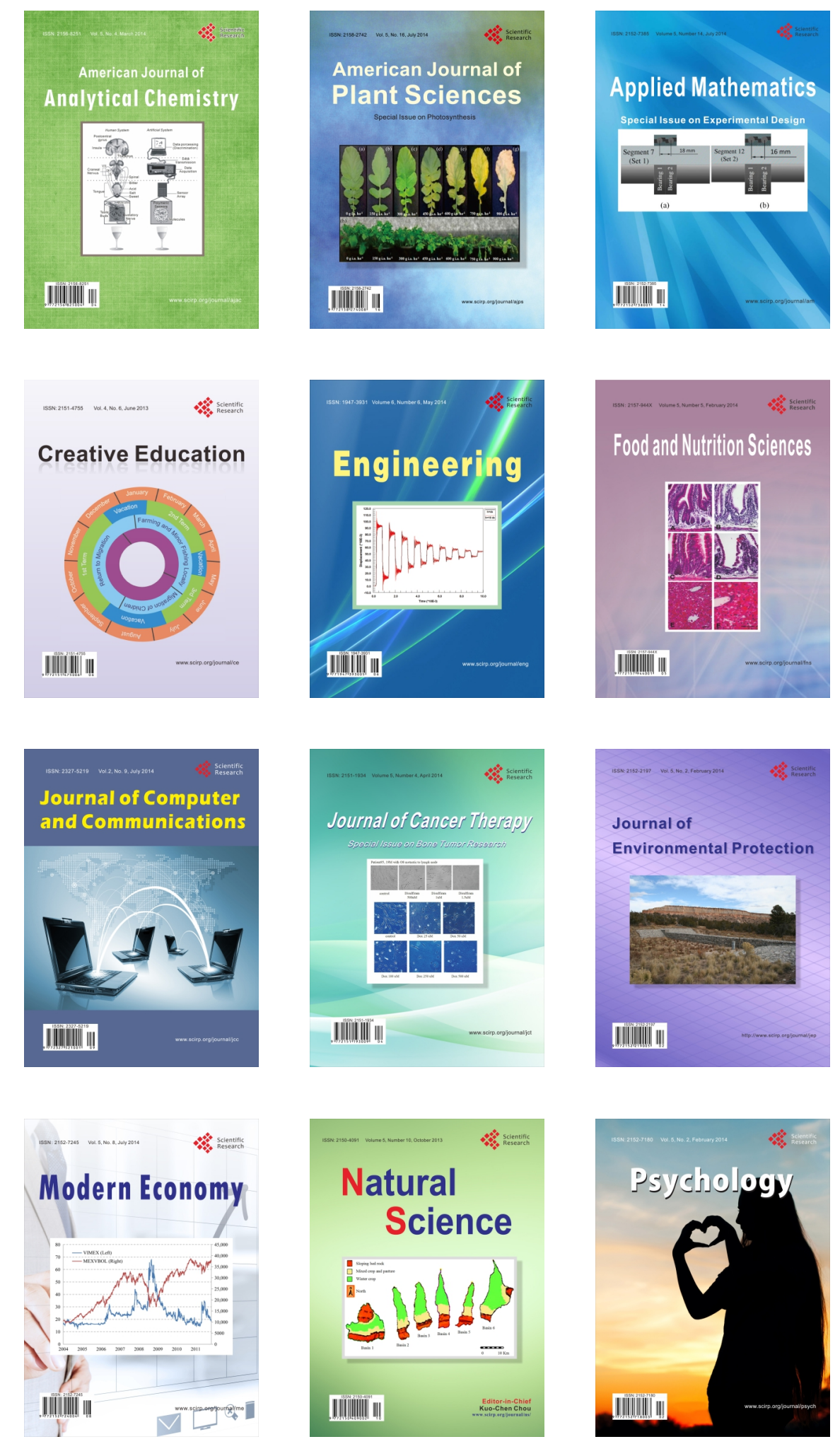